\title{
Research on Fuel Tank Model Selection of LNG Power Ship Based on Evaporation Rate Control and Construction Cost
}

\author{
WANG Yunlong ${ }^{1, a^{*}}$, YUN Yanyun ${ }^{1}$, CHEN Yonglin ${ }^{1}$, LIN Yan ${ }^{1}$, JIN Chaoguang ${ }^{1}$ \\ ${ }^{1}$ School of Naval Architecture, Dalian University of Technology, Dalian, China, 116024 \\ ayunlongw@dlut.edu.cn
}

Keywords: LNG power ship, Fuel tank, Evaporation rate, ANSYS finite element analysis

\begin{abstract}
With the increase of LNG power ship, the structure form of the fuel tank has been paid more attention. In this paper the advantages and disadvantages of LNG powered ship fuel tank with double shell tank structure or independent $C$ type single shell tank structure are discussed from the initial evaporation rate control and the construction cost. According to the characteristics of the fuel tank for LNG power ship, the weight of the steel structure for the double shell fuel tank and the single shell fuel tank is calculated based on the design of four different kinds of fuel tanks, and the evaporation rate is simulated and predicted by use of ANSYS finite element software. Through the comparative analysis, it is found that the two kinds of structure can both meet the requirements of the specification. Under the condition of the same volume, shape and thickness of the insulation layer, the weight of the double shell tank structure is about two times as that of the single shell tank structure, while the evaporation rate about a quarter.
\end{abstract}

\section{Introduction}

In order to effectively control the pollution in the sea, International Maritime Organization has issued the relevant provisions. It is stipulated that the average sulfur content of heavy oil should be reduced from the current $4.5 \%$ to $0.5 \%$ in 2020 , and the average sulfur content in the fuel oil should decrease to $0.1 \%$. In addition, the diesel engine NOx emission standards are also getting higher and higher, while the diesel oil is difficult to meet these requirements as fuel [1]. LNG has obvious advantages in terms of security, economy and environmental protection, and gradually becomes the first choice for future marine fuel [2, 3]. However, the selection and optimization design of fuel tank for LNG power ship have been the focus and difficulties among the industry debate [4]. In this paper, the advantages and disadvantages of two kinds of fuel tanks are discussed from two aspects which are the initial evaporation rate control and the construction cost of the fuel tank, and give a useful reference for the selection and optimal design of the fuel tank for LNG power ship.

\section{Characteristics Analysis of Fuel Tank for LNG Power Ship}

Compared to conventional ship fuel tank, LNG fuel tank has the following special requirements: ultra low temperature, high security requirements and good thermal insulation performance [5].

Fuel Tank with Double Shell Structure. In order to prevent the leakage of LNG, LNG storage tank must have high security. API and BS both require that it must have a double shell structure, which means when the inner shell is damaged, the outer shell can still provide protection [6]. At present, most of the LNG power ships are using the double shell structure.

Double shell tank consists of inner shell, outer shell and thermal insulation layer made of internal support and heat preservation material. Because the shell requires a protective effect, the shell also chooses low temperature resistant material. At present, the vacuum powder insulation is widely used in the double-layer tank. Powder or fiber with low thermal conductivity is filled between the two shells. the double layer shell is pumped into a vacuum to eliminate the gas convection heat transfer [7]. The load transfer method of double shell fuel tank is shown in Fig. 1. The design of the tank structure is decided by the load transfer mode of dual fuel tanks. 


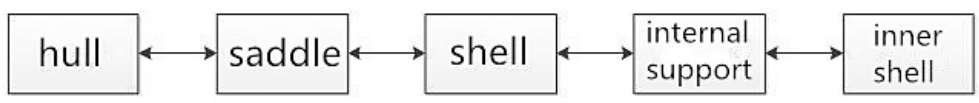

Fig. 1 Load translation direction of double shell tank.

Fuel Tank of Single Shell Structure. Independent C type single shell tank is widely used in medium and small sized LNG transport ships. The volume of single cylinder $\mathrm{C}$ type independent tank varies from 1000 cubic meters to 6000 cubic meters and has been applied in ships. The inner shell is the same as the double deck. The heat insulating layer generally uses polystyrene thermal insulation board with a certain thickness, and can be bonded by special adhesive to the outer surface of the liquid tank. Set $0.25 \sim 0.5 \mathrm{~mm}$ galvanized steel sheet in the outermost layer to protect the polystyrene foam. The tank wall is connected with the hardwood steel structure by low conductive saddle. The load transfer of single shell tank is shown in Fig. 2.

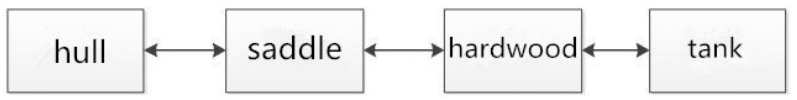

Fig. 2 Load translation direction of single shell tank.

\section{The Comparison of Weight for Tank Steel Structure}

This paper has simplified the problem: double shell fuel tank only considerers the structure weight of the inner shell and the outer shell, and single shell fuel tank only considerers the weight of steel structure. The mass of other structures has little impact on total mass and the cost of steel structure. In order to carry out the comparison, four kinds of fuel tanks are designed the volume is $600 \mathrm{~m}^{3}, 800 \mathrm{~m}^{3}, 1000 \mathrm{~m}^{3}$ and $1200 \mathrm{~m}^{3}$ respectively. These LNG fuel tanks are cylindrical, end socket is standard ellipsoid, and cylinder length is 2 times as long as the diameter of the cylinder. The specific parameters are shown in Table 1 .

Table 1. Parameters of the LNG fuel tanks.

\begin{tabular}{|c|c|c|c|c|c|c|c|c|}
\hline \multirow[b]{2}{*}{ LNG fuel Tanks } & \multicolumn{2}{|c|}{$\begin{array}{c}\text { NO.1 } \\
\Phi 6900 \times 13800 \\
\end{array}$} & \multicolumn{2}{|c|}{$\begin{array}{c}\text { NO.2 } \\
\Phi 7600 \times 15200 \\
\end{array}$} & \multicolumn{2}{|c|}{$\begin{array}{c}\text { NO.3 } \\
\Phi 8200 \times 16400 \\
\end{array}$} & \multicolumn{2}{|c|}{$\begin{array}{c}\text { NO.4 } \\
\Phi 8700 \times 17400 \\
\end{array}$} \\
\hline & $\begin{array}{c}\text { Double } \\
\text { layer } \\
\text { tank }\end{array}$ & $\begin{array}{c}\text { Single } \\
\text { layer } \\
\text { tank }\end{array}$ & $\begin{array}{c}\text { Double } \\
\text { Layer } \\
\text { tank }\end{array}$ & $\begin{array}{c}\text { Single } \\
\text { layer } \\
\text { tank }\end{array}$ & $\begin{array}{c}\text { Double } \\
\text { Layer } \\
\text { tank }\end{array}$ & $\begin{array}{c}\text { Single } \\
\text { Layer } \\
\text { tank }\end{array}$ & $\begin{array}{c}\text { Double } \\
\text { Layer } \\
\text { tank }\end{array}$ & $\begin{array}{r}\text { Single } \\
\text { Layer } \\
\text { tank }\end{array}$ \\
\hline designed volume, $\mathrm{m}^{3}$ & 600 & 600 & 800 & 800 & 1000 & 1000 & 1200 & 1200 \\
\hline diameter of inner shell, $\mathrm{mm}$ & 6900 & 6900 & 7600 & 7600 & 8200 & 8200 & 8700 & 8700 \\
\hline cylinder length, mm & 13800 & 13800 & 15200 & 15200 & 16400 & 16400 & 17400 & 17400 \\
\hline Designed pressure of inner shell, MPa & 1 & 1 & 1 & 1 & 1 & 1 & 1 & 1 \\
\hline Working pressure of inner shell, MPa & 0.8 & 0.8 & 0.8 & 0.8 & 0.8 & 0.8 & 0.8 & 0.8 \\
\hline Working pressure of outer shell, $\mathrm{MPa}$ & -0.1 & - & -0.1 & - & -0.1 & - & -0.1 & - \\
\hline material of inner shell & $9 \mathrm{Ni}$ & $9 \mathrm{Ni}$ & $9 \mathrm{Ni}$ & $9 \mathrm{Ni}$ & $9 \mathrm{Ni}$ & $9 \mathrm{Ni}$ & $9 \mathrm{Ni}$ & $9 \mathrm{Ni}$ \\
\hline material of outer shell & $9 \mathrm{Ni}$ & - & $9 \mathrm{Ni}$ & - & $9 \mathrm{Ni}$ & - & $9 \mathrm{Ni}$ & - \\
\hline
\end{tabular}

Weight Calculation of the Inner Shell. The design of the inner shell thickness of the double-layer tank is determined through calculation according to the inner pressure that it can bear. The thickness of the cylinder and end socket can be confirmed after the size, material and designed pressure of inner shell are designated. According to the relevant specification, the allowable stress $[\sigma]$ of the $9 \mathrm{Ni}$ steel is $252 \mathrm{Mpa}$ [7] when the temperature is below $20^{\circ} \mathrm{C}$. According to the requirements of The Rules for Classification of Sea-going Steel Ships ${ }^{[8]}$, the Eq.1 is used for calculating the wall thickness of the internal pressure cylinder:

$$
\delta=p D_{0} /(2[\sigma]-p)+0.75 \quad \mathrm{~mm}
$$

In the formula, $p$ is designed pressure $\mathrm{MPa} ; D_{0}$ is Shell diameter, $\mathrm{mm}$; $[\sigma]$ is allowable stress, $\mathrm{N} /$ 
$\mathrm{mm}^{2} ; \varphi$ is the welding joint coefficient, where $\varphi=1$.

the Eq. 2 is used for calculating the thicknes of internal pressure elliptical head.

$$
\delta=p D_{1} y / 2[\sigma]+0.75 \quad \mathrm{~mm}
$$

In the formula, $D_{1}$ is outer diameter of end socket, $\mathrm{mm} ; y$ is shape factor, for the ellipsoidal head, this paper takes $\mathrm{y}=1$ for simplified calculation.

Weight Calculation of Outer Shell Structure. The design of the outer shell thickness of the double-layer tank is determined through calculation according to the outer pressure that it can bear. The outer shell thickness is calculated according to the graphical calculation of the wall thickness of the external pressure cylinder in GB 150.1-2011 Pressure Vessel [9].

Weight Comparison of Tank Structure. The structural weights of the two kinds of fuel tanks are summarized in Fig. 3. It can be seen that when the other design parameters are same, the weight of the two kinds of fuel tank's steel structure increases linearly as the volume increases, and the steel structure mass of double shell tank is two times as heavy as single shell tank when the volume is same. The structure of single shell LNG fuel tank is simpler than the previous double shell tank and is easier to manufacture so that the cost also becomes a great advantage.

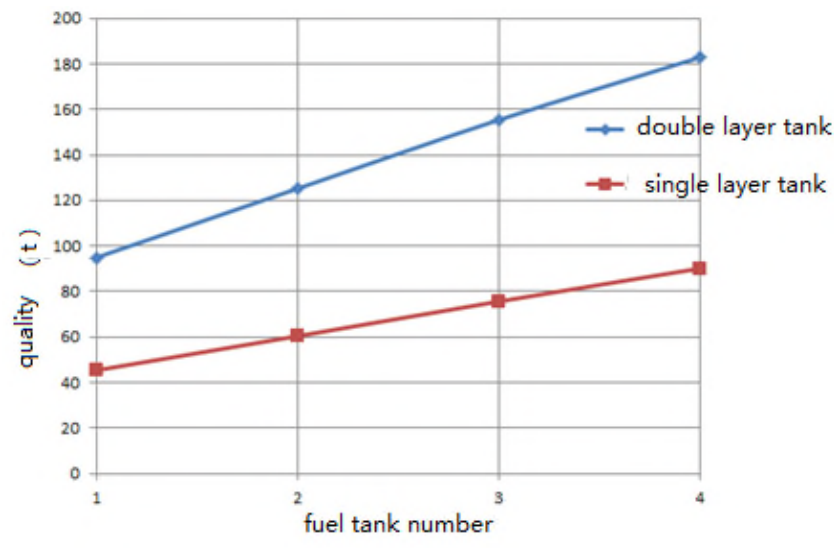

Fig. 3 Weight comparison of the steel structure of the fuel tanks.

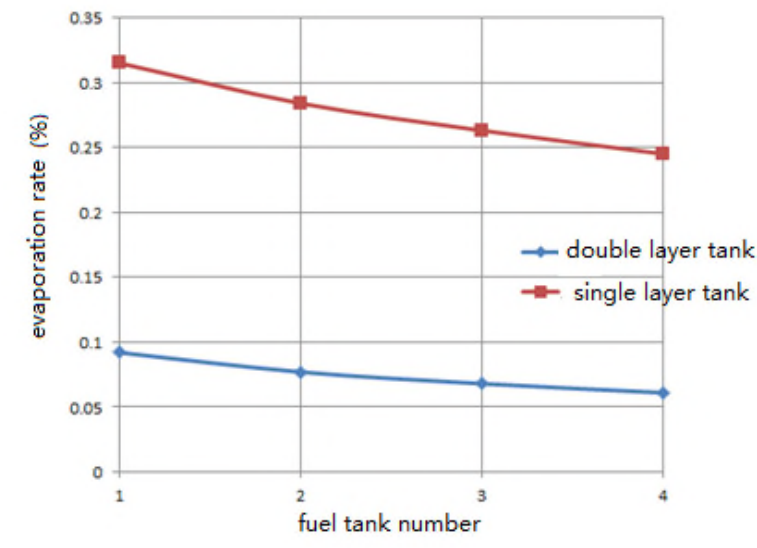

Fig. 4 Initial evaporation rate comparison of the fuel tanks.

\section{Comparison of Initial Evaporation Rates}

After LNG power vessel fuel tank is filled, it keeps the heat exchange with the outside world. Insulation layer of LNG fuel tank is designed to minimize the heat exchange to fuel tank from thermal convection, heat conduction, heat radiation and other heat transfer processes, to maintain the normal condition of low temperature system.

Initial Evaporation Rate Calculation. An important parameter for evaluating the thermal insulation of cargo tanks is the evaporation rate. The evaporation rate $\eta_{\text {bor }}$ is the percentage of the cryogenic liquid vaporized in the total mass of cargo in $24 \mathrm{~h}$, referring with Eq. 3.

$$
\eta_{\text {bor }}=m_{1} / m \times 100 \%
$$

In the formula, $m_{1}$ is the mass of the cryogenic liquid evaporated in $24 \mathrm{~h} ; m$ is the total liquid cargo mass in liquid tank.

The IMO standard states that the evaporation rate of a $125,000 \mathrm{~m}^{3} \mathrm{LNG}$ vessel is $0.12 \%$ per day. The daily evaporation rate of large-scale LNG carriers should be controlled below $0.15 \%$. The evaporation rate of medium and small LNG carriers is higher, and the requirement is to control the rate below $0.3 \%$ [10]. Fuel tanks of LNG power vessel are designed with reference to the relevant requirements of small and medium LNG carriers.

When the fuel tank achieves to a steady state, the calculation formula of evaporation rate can be obtained from heat balance equation, referring to Eq. 4: 


$$
B=\frac{g}{G}=\frac{3600 \times 24 \times Q}{\rho V \gamma} \times 100 \%
$$

In the formula: $Q$ is total heat flux of the fuel tank; $\gamma$ is the latent heat of vaporization at the boiling point of LNG under normal atmospheric pressure; $g$ is LNG evaporation in $24 \mathrm{~h} ; \rho$ is the density of LNG; $V$ is tank capacity of cargo tanks.

At present, there are two methods commonly used to calculate the heat flow of LNG cryogenic fuel tank, one is the theoretical calculation, the other is the software analysis. In this paper, ANSYS software is used to calculate. The software is based on the thermal equilibrium equation of the energy balance principle, using the finite element method to calculate the temperature of each node and deriving other thermal physical parameters [11]. The relevant parameters of the model are shown in Table 2.

Table 2. Relative parameters of the model.

\begin{tabular}{ccc}
\hline parameters & double layer tank & single layer tank \\
\hline insulation material & vacuum powder & rigid polyurethane foam \\
insulation thickness, $\mathrm{mm}$ & 300 & 300 \\
heat transfer coefficient of material, $\mathrm{W} /\left(\mathrm{m} \cdot{ }^{\circ} \mathrm{C}\right)$ & 0.0065 & 0.023 \\
internal heat transfer coefficient, $\mathrm{W} /\left(\mathrm{m} \cdot{ }^{\circ} \mathrm{C}\right)$ & 15 & - \\
hardwood heat transfer coefficient, $\mathrm{W} /\left(\mathrm{m} \cdot{ }^{\circ} \mathrm{C}\right)$ & - & 0.18 \\
air convection coefficient & 2.3 & 2.3 \\
ambient temperature, ${ }^{\circ} \mathrm{C}$ & 5 & 5 \\
temperature of $\mathrm{LNG},{ }^{\circ} \mathrm{C}$ & -163 & -163 \\
density of $\mathrm{LNG}, \mathrm{kg} / \mathrm{mm}^{3}$ & 500 & 500 \\
LNG's latent heat of vaporization, $\mathrm{kJ} / \mathrm{kg}$ & 511 & 511 \\
\hline
\end{tabular}

By applying a fixed temperature constraint to the interior of the insulation layer and convection boundary conditions to the outside of the insulation, the temperature field of the insulation layer can be obtained. Taking NO.1 fuel tank as an example, Fig. 5 and Fig. 6 show the temperature field distribution of double shell fuel tank.

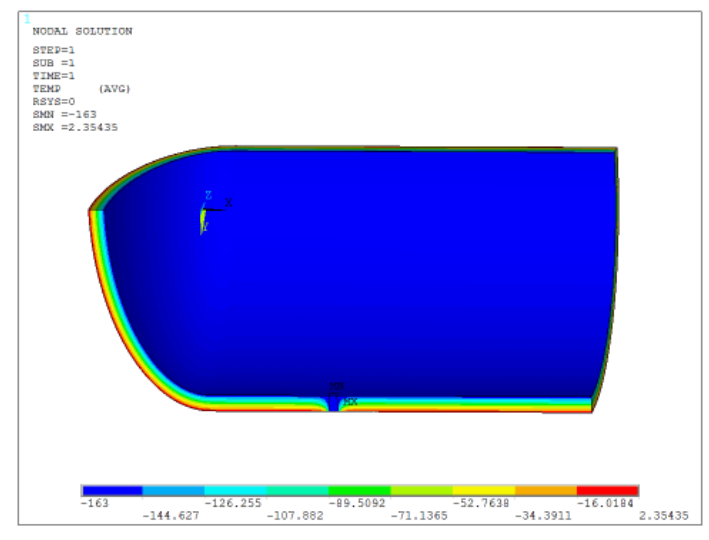

Fig. 5 Temperature distribution of NO.1 double shell tank (inner side).

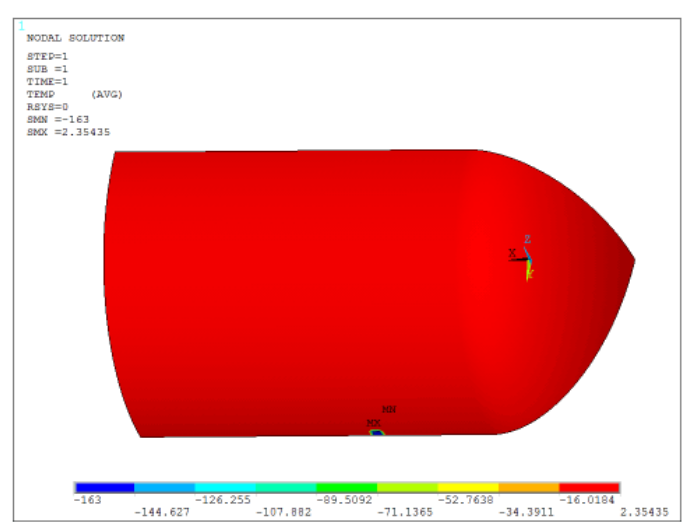

Fig. 6 Temperature distribution of NO.1 double shell tank (outer side).

The calculation results of initial evaporation rate are showed in Fig. 4. It can be seen that insulation efficiency of double shell tank is better than that of single shell tank because heat transfer coefficient of double shell tank is lower. Meanwhile, as the value of the evaporation rate and the ratio of fuel tank's volume to surface area is inversely proportional, in terms of same shape of the fuel tank, the initial evaporation rate decreases as the volume increases. NO.1 single layer tank has a capacity of $600 \mathrm{~m}^{3}$, but its daily evaporation rate is higher than $0.3 \%$, therefore, it's necessary to consider thickening insulation layer or choosing a lower thermal conductivity insulation materials, 
while the other seven tank forms can meet the daily evaporation rate requirement of not more than $0.3 \%$.

\section{Conclusion}

For the industry argument on the fuel tank selection of LNG power ship, in this paper, four types of the volumes of the double shell tanks and single shell tanks are designed, calculated and compared from the fuel tank material costs and the initial evaporation rate points of view. In terms of material cost, the double shell fuel tank is twice as much as a single shell fuel tank in the same volume and shape, and double shell tank's manufacturing process is also more difficult than single shell tank's. In terms of initial evaporation rate, the insulation performance of double shell tank is better than single shell tank, because the heat transfer coefficient of vacuum powder is lower than that of rigid polyurethane foam. The evaporation rate of Single shell fuel tank is about four times as much as the double shell fuel tank in the same volume, shape and insulation layer thickness. Through the research, it can be found that for small ships, double shell tank construction is recommended because of their short voyage duration, long berth time and small size fuel tank required; however, for large ocean-going vessels, single shell tank construction is recommended due to their long continuous supply time, short berth time and large size fuel tank required.

\section{Acknowledgment}

The study are supported by the National Natural Science Foundation of China (No. 51209034), the Natural Science Foundation of Liaoning Province(No.201402007).

\section{References}

[1] J. Y. Xu. Research on R \& D and Test of LNG Fuel - Power Ship. Beijing, CCS, 2013.

[2] J. H. Yang. Research on Filling Technology of LNG Power Ships. Marine Eng. Equip. Tech. 1(3) (2014) 263-266.

[3] B. Y. Jin, X. L. Zheng. Design and Research of LNG Dual Fuel Powered Harbor Tug. Naval Archit. Ocean Eng. (2) (2013) 35-39.

[4] J. H. Kim, J. H. Choi, S. G. Park, Structural Development of LNG Fueled Large Container Ship. ASME 2013 32nd International Conference on Ocean, Offshore and Arctic Engineering, OMAE 2013, Nantes, France. June, 2013, pp. 380-389.

[5] C. Li. Research on Selection of Storage Tank and Stable Pressure Process of LNG Power Ship. Dalian: Dalian Maritime University, 2013.

[6] CCS. Specification for Natural Gas Powered Ships. 2013.

[7] D. F. Gao. Research on Structure Optimization and Self-pressurization Process of $20 \mathrm{~m}^{3} \mathrm{LNG}$ Storage Tank. Harbin: Harbin Institute of Technology, 2007.

[8] CCS. Rules for Classification of Sea-going Steel Ships. Beijing: China Communications Press, 2012.

[9] National Standards of People's Republic of China. GB150.1-2011[Z]. 2011.

[10] L. Qiu. Thermal Insulation Technology and Heat Transfer Calculation of LNG Cargo Tank. Shanghai: Shanghai Maritime University, 2004.

[11] X. M. Wang. ANSYS Numerical Analysis of Engineering Structure. Beijing: China Communications Press, 2012. 